\title{
СОПОСТАВИТЕЛЬНЫЙ АНАЛИЗ ГЛАГОЛОВ С СЕМАНТИКОЙ ЧРЕЗМЕРНОЙ ИНТЕНСИВНОСТИ ДЕЙСТВИЯ В РУССКОМ И ПОЛЬСКОМ ЯЗЫКАХ
}

\author{
ANALIZA PORÓWNAWCZA CZASOWNIKÓW \\ OZNACZAJĄCYCH NADMIERNĄ INTENSYWNOŚĆ \\ CZYNNOŚCI W JĘZYKU ROSYJSKIM I POLSKIM \\ A COMPARATIVE ANALYSIS OF THE VERBS \\ WITH THE MEANING OF THE EXCESSIVE INTENSITY \\ OF ACTION IN RUSSIAN AND POLISH
}

\author{
Daniel Dzienisiewicz \\ Uniwersytet im. Adama Mickiewicza w Poznaniu, Poznań - Polska, \\ daniel.dzienisiewicz@gmail.com
}

\begin{abstract}
The article is an attempt to present the characteristics of Russian and Polish verbs with the meaning of the excessive intensity of action in a possibly concise form. The analyzed lexical units have been retrieved from Russian and Polish dictionaries on the basis of the existing source literature and the author's own investigations. The aim of the article is to compare the word-formative structure of the verbs and analyze their semantics on the basis of the prefixes occurring in the lexical material. The quantitative and qualitative analyses have been conducted. The cases of word-formative synonymy have been described and the largest groups of lexical synonyms have been highlighted.

Ключевые слова: русские глаголы, польские глаголы, словообразование, словообразовательная синонимия, словообразовательный тип, глагольная префиксация, суффиксация, постфиксация.

Słowa kluczowe: rosyjskie czasowniki, polskie czasowniki, słowotwórstwo, synonimia słowotwórcza, typ słowotwórczy, prefiksacja czasownikowa, sufiksacja, postfiksacja.

Keywords: Russian verbs, Polish verbs, word-formation, word-formative synonymy, word-formative type, verbal prefixation, suffixation, postfixation.

Глаголы представляют один из наиболее обширных пластов русской и польской лексики. У большого количества глагольных слов, выражающих процессы, состояния, действия и отношения, наблюдается огромное богатство значений. Иногда семантические оттенки являются настолько тонкими, что обнаруживаются разногласия в подходах к классификации некоторых глагольных единиц. Трудности вызывает также многообразие подходов к изучению словообразования глаголов. Как замечает М. Рутковска,
\end{abstract}


Słowotwórstwo czasowników stanowi kuszącą problematykę, która nastręcza ogromną liczbę zagadnień rozwiązywanych w różny sposób przez różnych autorów. Nie sądzę, ażeby w najbliższym czasie wszystkie te zagadnienia zostały rozwiązane w sposób jednolity i ostateczny1.

Глаголы со значением интенсивности действия не являются исключением из этого правила. В пределах данной группы выделяется широкий круг слов, указывающих как на недостаточную (недогрузить, недоесть, недосолить), так и на чрезмерную или крайнюю интенсивность совершаемого действия (перегрузить, переесть, пересолить). Кроме того, с одной стороны, мы имеем дело со множеством морфем, наличествующих в глагольных единицах данной группы, с другой - с еще большим количеством семантических оттенков, так как часто среди дериватов с одним и тем же префиксом наблюдаем некоторые колебания в значениях. Предметом нашего интереса в данной статье будет малоисследованная группа русских и польских глаголов, обозначающих чрезмерную интенсивность действия². Учитывая обширность темы и сложность некоторых вопросов, в статье будут затронуты лишь некоторые особенности словообразовательных типов, обнаруженных в собранном материале, а именно избранные сведения о семантике, словообразовательной структуре и продуктивности, а также случаях лексической и словообразовательной синонимии. Статья представляет отчет по проведенному эмпирическому исследованию данной лексико-семантической группы глаголов.

\section{1. Структурные типы русских глаголов}

Подробное исследование русских глаголов позволяет создать классификацию глаголов на основании префиксов, содержащихся в их словообразовательной структуре. Можно выделить одиннадцать приставок, входящих в состав группы глаголов со значением чрезмерной интенсивности действия. Это префиксы пере-, за-, из-/изо-, до-, на-, y-, о-(об-), от-, вы-, с- и пре-.

${ }^{1}$ M. Rutkowska, Nie znane polszczyźnie rosyjskie prefigowane derywaty odczasownikowe z elementem "-sja" typu "doležat'sja”, "priest'sja", Wrocław 1981, c. 5.

2 Анализу были подвергнуты 331 русский и 374 польских глагола, почерпнутые из трех словарей: Большой толковый словарь русского языка, под ред. С. А. Кузнецова, Санкт-Петербург 1998, [в:] электронный ресурс: www.gramota.ru (06.12.2015); Stownik Języka Polskiego PWN, pod red. M. Szymczaka (в дальнейшем SJP), [в:] электронный ресурс: http://sjp.pwn.pl (06.12.2015); Stownik jezzyka polskiego, pod red. W. Doroszewskiego (в дальнейшем SJPDor), [в:] электронный ресурс: http://sjp.pwn.pl (06.12.2015). Учитывая обширность исследовательского материала и ограничения по объему этой статьи, при описании каждого префикса приводится лишь несколько примеров с целью проиллюстрировать проблему. 
Наиболее продуктивным префиксом, наличествующим в русских глаголах с семантикой чрезмерной интенсивности действия, является префикс пере- (28,13\% всех единиц). Среди глаголов, содержащих в своей структуре эту приставку можно выделить две семантические группы: 'чрезмерно интенсивно воздействовать на объект' (напр.: перебелить, перекалить, пересолить), а также 'чрезмерно интенсивно осуществиться деятельности, процессу или состоянию' (напр.: перекваситься, перекиснуть, переработаться). Большинство дериватов (более 95\%) образовано приставочным способом, ср. пере-baрить, пере-греть, пере-кипеть (в том числе и отдельные случаи первично-префиксальных глаголов типа пере-насытить, пере-утомить). Существуют также редкие случаи префиксально-постфиксальных глаголов. Это прежде всего глаголы, относящиеся ко второй семантической группе - типа пере-работать-ся, а также отыменных префиксально-суффиксальных (пере-сыт-и-ть) и префиксально-суффиксально-постфиксальных глаголов (пере-сыт-и-ть-ся).

В случае глаголов с префиксом за- (21,10\% всех единиц) так же, как и у глаголов с приставкой пере-, мы имеем дело с двумя семантическими группами, а именно: со словами со значением 'неумеренно-интенсивно воздействовать на живое существо' (напр.: закуnать, запороть, засечь) и со словами со значением 'неумеренно увлечься, выйти за допустимые или желаемые пределы' (напр.: забегаться, зазубриться, залечиться). Однако, по нашему мнению, к группе глаголов с префиксом за- можно отнести также глаголы с семантикой неумеренно интенсивного воздействия на неодушевленную среду типа засластить ('сделать сладким или слаще; сделать слишком сладким'), застирать ('испортить плохой или многократной стиркой'), а также изношенности одежды типа заносить ('истрепать, загрязнить продолжительной ноской') и затрепать ('привести в негодность длительным или небрежным употреблением, истрепать; // частым употреблением в речи, в печати и т. п. лишить новизны, остроты'). Почти 80\% дериватов образовано префиксальным способом, напр.: за-купать, за-морить, за-пилить. Остальные глаголы имеют префиксально-постфиксальную структуру. Это прежде всего глаголы со значением неумеренного увлечения типа за-говорить-ся, за-писать-ся, за-танцевать-ся.

3 Приводимые в статье значения отдельных словообразовательных типов почерпнуты из следующих источников: Русская грамматика, под ред. Н. Ю. Шведовой, т. 1, Москва 1980; М. В. Черепанов, Очерк словообразовательной типологии русского глагола: монография, Саратов 2004; A. Bogusławski, Prefiksacja czasownikowa we wspótczesnym języku rosyjskim, Wrocław 1963; W. Śmiech, Derywacja prefiksalna czasowników polskich, Wrocław 1986; Gramatyka wspótczesnego jezzyka polskiego. Morfologia, pod red. R. Grzegorczykowej, R. Laskowskiego i H. Wróbla, Warszawa 1984. 
Третий по продуктивности префикс - из-/ изо- (12,84\% всех единиц) - также выступает в глаголах двух семантических групп. Глаголы, имеющие префиксальную структуру, обладают значением 'уничтожить, нанести физический или нравственный ущерб живому существу', напр.: избаловать, измаять, истомить. Префиксально-постфиксальные глаголы имеют значение 'дойти до нежелательного состояния (утомления, негодности, исчерпанности), приобрести или утратить определенные качества, способности или привычки в результате частого, длительного или интенсивного совершения действия, названного мотивирующим глаголом', напр.: избегаться, износиться, исхлестаться. Кроме того, находим также чисто приставочные глаголы со значением доведения до нежелательного состояния предметов неодушевленной природы типа износить, истоптать, uстрепать. Почти 75\% всех глаголов данной группы составляют приставочные глаголы типа из-баловать, из-морить, из-мучить. Остальные 25\% это глаголы префиксально-постфиксальной структуры, напр.: из-носить-ся, из-ъездить-ся, ис-таскать-ся.

Довольно интересный случай представляют глаголы с префиксом до- (11,62\% всех единиц), не имеющие эквивалентов в польском языке. В отличие от предыдущих случаев данные единицы обладают одним значением, а именно: 'довести себя до неприятных последствий путем интенсивного совершения действия, названного мотивирующим глаголом', - и имеют прежде всего префиксально-постфиксальную структуру (более 70\% единиц типа до-пить-ся, до-читать-ся, до-цутить-ся), реже префиксальную (до-кататься, до-крутиться, до-смеяться).

Префикс $\boldsymbol{н} \boldsymbol{a}$ - выступает в структуре 10,09\% всех глаголов. Префиксальные глаголы имеют значение 'интенсивно проявить деятельность, совершив в избытке нечто нежелательное', напр.: намаять, наморить, напоить. Глаголы префиксально-постфиксальной структуры обладают значением 'совершить действие, названное мотивирующим глаголом, в достаточной степени или в избытке; дойти до состояния удовлетворения или пресыщения в результате длительного или интенсивного совершения этого действия', напр.: набегаться, накуриться, находиться. В данной группе преобладают префиксально-постфиксальные глаголы (более 65\% единиц типа на-пахать-ся, на-страдать-ся, на-ходить-ся).

Глаголы с префиксом $y$ - составляют 6,12\% исследовательского материала и обладают двумя значениями. Первое из них - это 'довести кого-, что-нибудь до нежелательного состояния (крайней усталости, бессилия, исчерпанности) с помощью действия, названного мотивирующим глаголом'. Данной семантикой обладают префик- 
сальные глаголы, напр.: y-гонять, y-катать, у-поить. Второе значение - это 'дойти до нежелательного состояния (крайней усталости, бессилия, исчерпанности) в процессе длительного или интенсивного действия, названного мотивирующим глаголом'. Это значение наблюдается у префиксально-постфиксальных глаголов типа y-бегать-ся, y-ездить-ся, у-ходить-ся. Преобладают приставочные глаголы, составляющие $70 \%$ всех единиц.

Глаголы с префиксом $\boldsymbol{b ы - ~ о б р а з у ю т ~ 3 , 0 6 \% ~ и с с л е д о в а т е л ь с к о г о ~}$ материала. Мы обнаружили случаи чисто префиксальных глаголов со значением чрезмерной интенсивности действия типа вы-bарить, bы-носить, bы-mоптать. Данные глаголы составляют бо́льшую часть всех глаголов с данной приставкой, поскольку выступают в структуре $70 \%$ дериватов. Кроме того, наличествуют формации с префиксом bы- и постфиксом -ся и имеют значение 'за длительное время, полностью совершить действие, названное мотивирующим глаголом; иногда также приобрести или утратить какие-нибудь свойства в результате этого действия', напр.: вы-бегать-ся, вы-носить-ся, вы-работать-ся.

Следующий тип - это глаголы с префиксом о-(об-) (2,14\% всех единиц). Тип префиксальных глаголов с приставкой об-(обо-) обладает значением ‘причинить ущерб кому-н. (иногда - обмануть кого-н.) с помощью действия, названного мотивирующим глаголом', ср. об-кормить, о-поить. Глаголы с префиксом о-(об-)- и постфиксом -ся составляют два подтипа со значениями: 1) o-...-ся - 'напиться чего-н. сверх меры' (о-пить-ся), 2) об-...-ся - 'совершить действие, названное мотивирующим глаголом, с излишней итенсивностью, причинив себе неприятность', напр.: объ-есть-ся, об-лопать-ся, обо-жрать-ся. Преобладают префиксально-постфиксальные глаголы (57,1\% дериватов). Чаще всего глаголы с данным префиксом обладают семантикой принятия пищи.

Глаголы с префиксом от- составляют 2,14\%. Все они образованы префиксальным способом и имеют значение 'довести до нежелательного состояния (повреждения, утомления) в результате действия, названного мотивирующим глаголом', напр.: от-сидеть, от-топать, от-ходить.

Морфема $c$ - выступает в 1,83\% всех единиц. Префиксальные глаголы с префиксом с- обладают значением 'уничтожить(ся), повредить(ся), израсходовать(ся) в результате действия, названного мотивирующим глаголом' (ср. сносить). Глаголы с префиксом си постфиксом -ся представлены двумя подтипами со значениями, относящимися к чрезмерной интенсивности действия: 1) 'дойти до нежелательного состояния, негодности в процессе длительного 
или интенсивного действия, названного мотивирующим глаголом' (сработать-ся), 2) 'в процессе длительной работы прийти в негодное состояние, истереться, износиться (об инструменте, механизме)' (сноситься). Глаголы с префиксально-постфиксальной структурой насчитывают более 65\% единиц, напр.: c-nuть-ся, с-работать-ся.

Глаголы с префиксом пре- составляют 0,93\% всех единиц. Тип глаголов с приставкой пре- выражает 'интенсивность, полноту (иногда чрезмерную) действия, названного мотивирующим глаголом'. В данной группе наблюдаются префиксальный глагол пре-увеличить, префиксально-суффиксальный глагол пре-сыт-и-ть и префиксально-суффиксально-постфиксальный глагол пре-сыт-и-ть-ся.

Отдельного рассмотрения заслуживают глаголы типа надорвать ('повредить что-л. от чрезмерного усилия, напряжения') и надсадить ('повредить в результате непосильного физического напряжения; надорвать'), которые с точки зрения современного русского языка являются немотивированными. Тем не менее семантика данных глаголов прямо указывает на их принадлежность к группе глаголов со значением чрезмерной интенсивности действия. От этих глаголов с помощью постфиксации образованы дериваты надорваться ('повредить что-л. себе от чрезмерного усилия, напряжения') и надсадиться ('повредить себе внутренние органы в результате чрезмерного напряжения; надорваться').

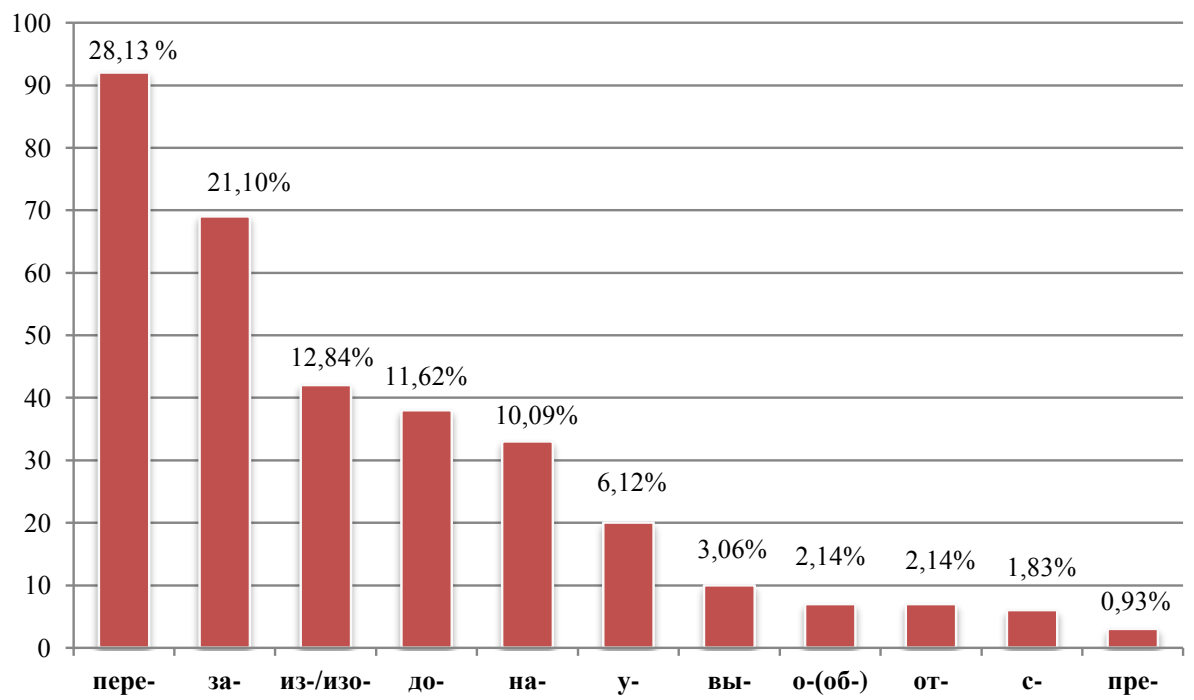

Диаграмма 1. Процентное соотношение префиксов русских глаголов 


\section{2. Структурные типы польских глаголов}

Среди польских глаголов, обозначающих чрезмерную интенсивность действия, наблюдается 11 префиксов. В состав данной группы входят приставки: prze-, $z a-, n a-, z(e)-,\left(s^{-}, s^{-}\right)-$, w $w y_{-}^{-}, u-, r o z(e)-$, $o \| o b(e)-, \operatorname{nad}(e)-$, po-, do--

Дериваты с приставкой prze- являются наиболее продуктивным типом, составляя 33,43\% всех единищ. Они выражают интенсивность, превышающую норму, ср.: przegrzać, przeidealizować, przeładować, przejeść się. Иногда данный префикс сообщает, что за пределы выходит количество вещества, названного в мотивирующей основе, напр.: przesolić (zupę), przeptacić (coś), przelać wodę, т. e. nalać za dużo wody). Более $80 \%$ единиц этой группы составляют приставочные глаголы, напр.: prze-ćwiczyć, prze-lać, prze-nawozić. Намного менее регулярны префиксально-постфиксальные (prze-ćwiczyć-się, prze-jeść-się, prze-trenować-się), префиксально-суффиксальные (prze-aniel-i-ć, prze-droż-y-ć, prze-jaskraw-i-c) и префиксально-суффиксально-постфиксальные глаголы (prze-chytrz-y-ć-się, prze-kwaś-i-ć-się, prze-ttuść-i-ć-się).

Глаголы с морфемой $z a-$ выступают в структуре $15,47 \%$ польских глаголов. Префиксальные глаголы с префиксом $z a-$ обладают общим значением 'убить, умертвить', напр.: zamęczyć, zabatożyć, zagło$d z i c ́$. Наблюдаются также префиксально-постфиксальные глаголы типа zamęczyć się, zamorzyć się, zapaść się. Преобладают префиксальные глаголы, составляющие более $70 \%$ глаголов с данной приставкой.

Глаголы с приставкой $\boldsymbol{n a}$ - наличествуют в составе $13,81 \%$ единиц. Среди польских дериватов с префиксом па- в специальной литературе выделяются два типа глаголов: 1) префиксальные глаголы со значением, указывающим на некоторую интенсивность действия, выражающуюся в дополнении или в затраченном усилии, напр.: nagotować [klusek], nakopać [torfu], nakwasić [ogórków]; 2) префиксально-постфиксальные глаголы со значением чрезмерной интенсивности действия, напр.: naczytać się [książek], nadyszeć się, nauganiać się. Из этого вытекает, что лишь второй тип глаголов указывает на чрезмерность действия. Однако в словарях представлены такие чисто приставочные глаголы, как nadręczyć ('zmęczyć kogoś, długo lub wielokrotnie mu dokuczając; też: zadać ból wielu ludziom lub zwierzętom' - SJP), nadźwigać ('wysilić się częstym dźwiganiem (kogo lub czego), nanosić się; dźwigając nanosić się czego' - SJPDor), namozolić (przestarz. 'mozolić kogo przez dłuższy czas, mozoląc zmęczyć kogo; natrudzić, namęczyć' - SJPDor), которые также могут выражать повышенную интенсивность. Разница между приставочными и префиксально-постфиксальными формациями заключается в том, что в то время 
как префиксальные глаголы выражают прежде всего длительность и многократность действия, префиксально-постфиксальные глаголы необязательно прямо указывают на эти признаки, cp. nachlać się (posp. 'upić się' - SJP), naćpać się (posp. 'najeść się do syta lub do przesytu' - SJP) nażreć się (posp. 'zjeść dużo i łapczywie' - SJP). Данным значением обладают глаголы, относящиеся к злоупотреблению едой и напитками, остальные препозитивно-постфиксальные глаголы указывают на долготу и многократность действия: nadenerwować się ('wielokrotnie lub przez dłuższy czas być zdenerwowanym' - SJP), nałazić sie ('zmęczyć się długotrwałym lub dalekim chodzeniem' - SJP), natańczyć sie ('spędzić dłuższy czas na tańczeniu; zmęczyć się tańcem' - SJPDor). В случае глаголов с префиксом па- чаще всего встречаются префиксально-постфиксальные глаголы $(78 \%)$.

Дериваты с приставкой $z(e)-,\left(s-, s_{-}\right)$выступают в 12,15\% глаголов. Среди многих типов глаголов с префиксом $z(e)-,\left(s-, s^{-}\right)$следует обратить внимание на глаголы с семантикой 'интенсивности, утомления действием', напр.: sfatygować, zganiać, zharować się. Существует также небольшая группа глаголов, обладающих значением 'уничтожить, израсходовать' (schodzić, znosić, zszargac). Большинство глаголов (более 55\%) имеют чисто префиксальную структуру.

Глаголы, содержащие в своей структуре приставку $w y-(7,73 \%$ всех единиц), образованы прежде всего префиксальным способом (более $70 \%$ глаголов типа wy-głodzić, wy-jeździć, wy-męczyc). Случаи префиксально-постфиксальных (wy-cierpieć-się, wy-robić-się, wy-trzeć-się) и префиксально-суффиксальных глаголов (wy-olbrzym'-i-ć, wy-szarz-a-ć) наблюдаются намного реже.

Глаголы с префиксом roz(e)- обладают значением достижения соответственной интенсивности действия. По нашим подсчетам данные единицы составляют 3,04\% материала. Семантика глаголов, входящих в состав этой группы, имеет оттенок чрезмерной интенсивности совершаемого действия, выражаемого мотивирующими лексемами. Чрезмерная интенсивность действия часто проявляется также в сверхмерной продолжительности времени, требуемого для исполнения данного действия. Составной частью этих дериватов является местоимение się, ср.: rozbrykać się, rozgadać się, rozgotować się. Наряду с префиксально-постфиксальными глаголами наблюдаются и префиксальные глаголы типа rozgotować, rozklapać, rozpieścić. Большинство глаголов $(54,5 \%)$ имеют префиксально-постфиксальную структуру.

Дериваты с морфемой $\boldsymbol{o}-\boldsymbol{\|} \boldsymbol{o b}(\boldsymbol{e})-(3,04 \%)$ - это формации со значением глубокого, всестороннего характера действия, происходящего от глаголов с семантикой охвата объекта действием, имеющих аб- 
страктный характер. Среди данной группы можно выделить маленькую группу переходных глаголов со значением чрезмерной интенсивности. Это прежде всего префиксальные и префиксально-постфиксальные глаголы со значением принятия пищи типа obeżré́ sie ('zjeść czego bardzo dużo, ponad miarę, najeść się do przesytu, objeść się (o ludziach - posp.)' - SJPDor), okarmić ('nakarmić kogo do przesytu lub do sytości' - SJPDor), ożłopać się (posp. 'opić się czego w zbyt dużej ilości; ochlać się - SJPDor). Кроме того, мы обнаружили два глагола, не вписывающиеся в эту схему: obciażyć ('nadmiernie coś eksploatować' - SJP) и oberwać (pot. 'nadwyrężyć się wskutek ciężkiej pracy, dźwignięcia czegoś; podźwigać się' - SJPDor). Преобладают префиксально-постфиксальные глаголы, выступающие в больше чем половине единиц.

Глаголы с приставкой $\operatorname{nad}(\boldsymbol{e})-$-, составляющие 2,76\% материала, относятся к действию, которое превышает ожидаемый объем. По наблюденям исследователей можно прежде всего выделить производные от переходных глаголов, ср. nadebrać ('brać więcej niż się należy, brać za wiele' - SJPDor), nadmierzyć ('dać ponad miarę, naddać przy mierzeniu' - SJPDor), nadważyć ('dołożyć komuś towaru ponad określoną wagę - SJP). В данной группе наблюдаем только префиксальные глаголы.

Кроме описанных типов глаголов существуют также немногочисленные примеры глаголов с префиксами $\boldsymbol{u}$ - $(6,08 \%), \boldsymbol{p o -}(2,21 \%)$ и do- $(0,28 \%)$. Значение чрезмерности действия, выражаемое этими глаголами не зафиксировано в грамматиках польского языка. Тем не менее лексическое значение данных единиц позволяет включить их в исследовательский материал. Это, к примеру, глаголы типа ubiegać się ('dużo biegając, zmęczyć się' - SJP), upić ('doprowadzić kogoś do stanu zamroczenia, namawiając go do wypicia nadmiernej ilości alkoholu' - SJP), pochlać się ('o wielu: upić się do nieprzytomności, schlać się, urżnąć się' - SJPDor), poobjadać się ('o wielu osobach: najeść się do przesytu, zjeść za dużo' - SJP), dopić się ('napić się do woli, przekroczyć miarę w piciu; upić się' - SJPDor).

Наряду с глаголами с четко выраженной словообразовательной структурой мы обнаружили также глаголы, являющиеся немотивированными в современном польском языке (ср. nabuzować sie, nabzdryngolić się, nadwyrężyć, przesadzić, wycieńczyć, wycieńnczyć się, usrać się, ubzdryngolić się, ululać się, urżnąć się), а также глагол przejrzeć со связанной основой. Эти глаголы включены в материал, поскольку их семантика указывает на чрезмерную интенсивность действия, ср. nabzdryngolić się (pot. 'upić sięe - SJP), wycieńczyć ('bardzo osłabić' - SJP), przejrzeć ('o roślinach i ich owocach: stać się zbyt dojrzałym' - SJP). 


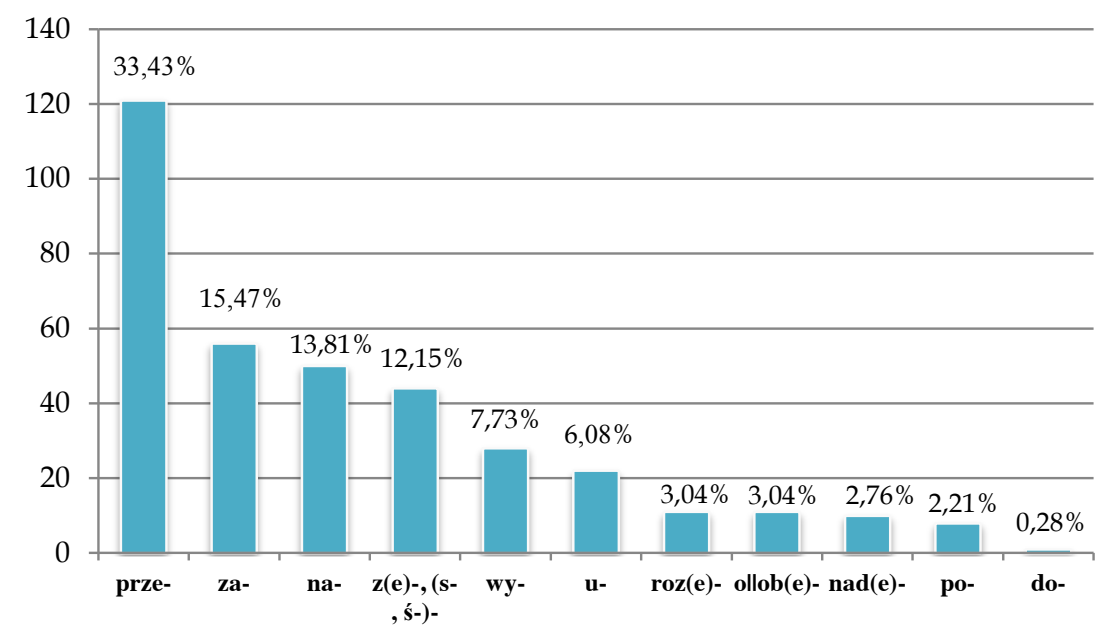

Диаграмма 2. Процентное соотношение префиксов польских глаголов

\section{3. Синонимия глаголов в русском и польском языках}

Исследование глаголов со значением чрезмерной интенсивности действия позволяет сделать интересные наблюдения в области синонимии, которая довольно сильно проявляется среди проанализированных единиц. Чтобы наиболее наглядно показать синонимические отношения, прежде всего следует обратить внимание на три лексико-тематические группы, в которых синонимия представлена особенно ярко.

Во-первых, богатство синонимов обнаруживается в группе глаголов с общим значением переутомления, ср.: вымотать, замаять, заморить, замотать, замучить, запарить, затиранить, измаять, изморить, измотать, измочалить, измучить, измытарить, истиранить, истомить, истощить, намаять, наморить, намучить, перемучить, перетомить, переутомить, укатать, уморить, умотать, умучить, утомить, yходumb; potrudzić, przemęczyć, sfatygować, sforsować, umęczyć, umordować, wycieńczyć, wyczerpać, wymęczyć, wyniszczyć, zamęczyć, zmordować.

К данной группе относятся и возвратные глаголы типа замаяться, замориться, замучиться, измаяться, измориться, измучиться, измытариться, истомиться, истощзиться, намаяться, намориться, намучиться, перемучиться, переутомиться, умориться, умотаться, упариться, утомиться; nadyszeć się, potrudzić się, przemęczyć się, sfatygować się, sforsować się, udyszeć się, umęczyć się, umordować się, usrać się, wycień- 
czyć się, wyczerpać się, wymęczyć się, wymordować się, wyniszczyć się, wyżytować się, zamęczyć się, zgrzać się, zmordować się, zszarpać się, zziajać się.

Наряду с вышеуказанными глаголами можно выделить ряд возвратных глаголов с более конкретным значением переутомления работой: выработаться, заработаться, наломаться, натрудиться, переработаться, перетрудиться, утрудиться; naharować się, namachać się, namordować się, napocić się, napracować się, narobić się, natyrać się, pomordować się, przepracować się, przerobić się, spracować się, urobić się, uszarpać się, utrudzić się, utyrać się, zaharować się, zaorać się, zapracować się, zatyrać się, zedrzeć się, zharować się, zmachać się.

Кроме того, внимание привлекают также разговорно-сниженные глаголы со значением злоупотребления спиртными напитками: надрызгаться, нажраться, накачаться, наклюкаться, налакаться, нализаться, нарезаться, наспиртоваться, нахлестаться; пабиzошас́ sie, nаbzdryngolić się, nachlać się, nagazować się, nawalić się, nażłopać się, ochlać się, ożtopać się, pochlać się, pochlać, schlać się, ubzdryngolić się, uchlać się, ululać się, upoić się, urżnać się, uwalić się, zachlać się, zachlać, zalać się.

В вышеприведенных примерах лексических синонимов нетрудно заметить много случаев словообразовательной синонимии, т. е. полной или частичной синонимии словообразовательных типов при наличии общей основы (ср. namordować się, pomordować się, umordować się, wymordować się, zmordować się) $)^{4}$. Среди анализируемых глаголов наличествуют синонимические ряды, содержащие от двух до шести глаголов. Наиболее многочисленной группой являются двухэлементные ряды (диады) типа: выварить - переварить, вывариться - перевариться, истоптаться - стоптаться, закачаться - перекачаться, догуляться - загуляться, заездить - уездить, закупать - перекупать, долежаться - залежаться, залечить - перелечить, доплясаться - заплясаться, достояться - настояться, дотанцеваться - затанцеваться, заучить - переучить, забаловать - избаловать, загоститься - перегостить, засластить - пересластить, затаскаться - истаскаться, затрепать - истрепать, затрепаться - истрепаться, изголодаться - наголодаться, затиранить - истиранить, намудрить - перемудрить, объесться - переесть; przegotować - rozgotować, przegotować sie - rozgotować się, nacierpieć się - wycierpieć się, schlastać - wychlastać, przeidealizować - wyidealizować, nastać się - wystać się, nabiegać się - ubiegać się, nadręczyć - zadręczyć, najechać się - ujechać się, nadyszeć się - udyszeć się, wyszarzać - zeszarzać, naładować - przeładować, natazić się - złazić się,

4 Однако не все слова с общей основой синонимичны, поскольку они могут обозначать два разных процесса (ср. обожра́ться 'Грубо. = Объесться', нажра́ться 'Грубо. Напиться пьяным'). Более подробно о словообразовательной синонимии см. Русская грамматика, указ. соч., т. 1, с. 140. 
namachać się - zmachać się, natańczyć się - stańczyć się, stańcować się - zatańcować się, nawalić się - uwalić się, nażłopać się - ożłopać się, nadlać - przelać, nadptacić - przeptacić, nadsolić - przesolić, obciażyć - przeciażyć, zszarpać się - uszarpać się, wysiedzieć się - zasiedzieć się (в общем по 23 ряды как в русском, так и в польском языках).

Помимо диад нередко наблюдаются также триады. В русскоязычном материале наличествует 15 трехэлементных рядов, в польском - 11, ср.: доработаться - заработаться - переработаться, бытоптать - истоптать - стоптать, выхвалить - захвалить - перехвалить, докататься - закататься - перекататься, докупаться - закупаться - перекупаться, докуриться - искуриться - накуриться, долечиться - залечиться - перелечиться, доучиться - заучиться - переучиться, замаять - измаять - нама́ять, зама́яться - изма́яться - нама́яться, заходиться - находи́ться - уходиться, истомиться - утомиться - переутомиться, натрудиться - перетрудиться - утрудиться, пересытить - перенасытить - пресытить, пересытиться - перенасытиться - пресытиться; objeść się - przejeść się - rozjeść się, wyjeździć - zajeździć - zjeździć, namordować - umordować - zmordować, natyrać się - utyrać się - zatyrać się, nachodzić się - schodzić się - uchodzić się, nagadać się - rozgadać się - zagadać się, naganiać się - uganiać się - zganiać się, naharować się - zaharować się - zharować się, spracować - upracować - zapracować, nażreć się - obeżreć się - przeżreć się, narobić się - przerobić się - urobić się.

В материале были обнаружены также тетрады (9 в русском и 6 в польском языке): вымотать - замотать - измотать - умотать, замучить - измучить - намучить - перемучить, замучиться - измучиться - намучиться - перемучиться, выносить - заносить - износить - сносить, выноситься - заноситься - износиться - сноситься, закормить - обкормить - окормить - перекормить, заморить - изморить - наморить - уморить, замориться - измориться - намориться - умориться, истомить - утомить - перетомить - переутомить; przemęczyć - wymęczyć - zamęczyć - zmęczyć, przemęczyć się - umęczyć się - wymęczyć się - zamęczyć się, nadźwigać się - podźwigać się - przedźwigać się - zdźwigać się, obkarmić - okarmić - przekarmić - zakarmić, napracować się - przepracować się - spracować się - zapracować się, opić się - przepić się - upić się - zapić się.

Наиболее редко встречаются пентады (по 2 ряда в русском и в польском языках): допиться - напиться - опиться - спиться - упиться, запоить - напоить - опоить - перепоить - упоить; namordować się - pomordować się - umordować się - wymordować się - zmordować się, napijać się - opijać się - przepijać się - upijać się - zapijać się; а также шестиэлементные модели, представленные одним рядом 
в обоих языках: выбегаться - добегаться - забегаться - избегаться - набегаться - убегаться; nachlać sie - ochlać sie - pochlać sie - schlać się - uchlać się - zachlać się.

Итак, на основе вышеприведенного анализа нужно сделать вывод, что семантика чрезмерной интенсивности действия в русском и польском языках представлена при помощи различных языковых средств, которыми располагают системы анализируемых языков. К словообразовательным способам, выступающим в этих формациях, следует отнести прежде всего префиксацию и префиксально-постфиксальный способ. Кроме того, можно отметить редкие случаи отыменных префиксально-суффиксальных и префиксально-суффиксально-постфиксальных глаголов, а также примеры немотивированных глаголов и глаголов со связанной основой. Изобилие словообразовательных формантов способствует появлению множества синонимических лексем, иногда вступающих в довольно протяженные ряды слов с близким значением. В общем, представленные в статье замечания могут оказаться небезынтересными для будущих трудов по лексикологии и словообразованию русских и польских глаголов. Особенно интересными кажутся сведения о продуктивности отдельных типов и указание на типы, недостаточно описанные в существующей специальной литературе.

\section{Библиография}

Большой толковый словарь русского языка, под ред. С. А. Кузнецова, Санкт-Петербург 1998, [в:] электронный ресурс: www.gramota.ru (04.05.2015).

Русская грамматика, под ред. Н. Ю. Шведовой, т. 1-2, Москва 1980.

Тихонов А.Н., Словообразовательный словарь русского языка в двух томах, Москва 1985.

Улуханов И. С., Словообразовательная семантика в русском языке и принципы ее описания, Москва 1977.

Черепанов М. В., Очерк словообразовательной типологии русского глагола: монография, Саратов 2004.

Bogusławski A., Prefiksacja czasownikowa we wspótczesnym języku rosyjskim, Wrocław 1963.

Gramatyka wspótczesnego jezzyka polskiego. Morfologia, pod red. R. Grzegorczykowej, R. Laskowskiego i H. Wróbla, Warszawa 1984.

Grzegorczykowa R., Zarys Stowotwórstwa polskiego. Stowotwórstwo opisowe, wyd. VI, Warszawa 1984.

Kaliszan J., Synonimia słowotwórcza rzeczowników w języku polskim i rosyjskim, Poznań 2000. 
Rutkowska M., Nie znane polszczyźnie rosyjskie prefigowane derywaty odczasownikowe z elementem "-sja" typu "doležat'sja”, "priest'sja”, Wrocław 1981.

Słownik gniazd stowotwórczych wspótczesnego jezyka ogólnopolskiego, t. 1-4, Kraków 20012004.

Stownik języka polskiego, pod red. W. Doroszewskiego, [в:] электронный ресурс: sjp.pwn.pl (06.12.2015).

Słownik Jezyka Polskiego PWN, pod red. M. Szymczaka, [в:] электронный ресурс: sjp.pwn.pl (06.12.2015).

Śmiech W., Derywacja prefiksalna czasowników polskich, Wrocław 1986. 